\title{
Más allá de la imagen: una mirada cercana a la ilustración editorial
}

\author{
Nayelli Herzel Arley Dávila
}

\section{Resumen}

El vasto universo de la ilustración y sus manifestaciones en diversos medios — publicidad, diseño de productos comerciales y culturales, internet y sus derivados, la industria textil y la editorial, entre otros - han dado lugar en los últimos años a un interés particular por su estudio y profesionalización en México. Con la intención de coadyuvar a ese objetivo, desde el ámbito editorial surge este breve estudio que plantea la comprensión de la ilustración más allá de su papel como elemento decorativo dentro del libro. En este artículo, nos acercamos a la ilustración a partir de su definición formal, orígenes, su desarrollo en México - a través de un brevísimo recorrido histórico-y sus estructuras comunicantes. Estas reflexiones casi nunca se realizan y constituyen el punto medular del ejercicio de la ilustración. Para reforzar este planteamiento y arrojar una visión más amplia sobre la ilustración como disciplina, los campos del diseño y la comunicación ayudarán a conformar las bases teóricas para su estudio formal. Asimismo, el énfasis que se hace en la figura del lector resulta fundamental para comprender el circuito gráfico y comunicativo de la ilustración, que la afianza como un lenguaje visual formal que rebasa a su contenedor, el libro, tendiendo puentes hacia la subjetividad.

Palabras clave: ilustración editorial, libros, literatura infantil, diseño, comunicación.

\section{BEyond IMAGE: A CLOSE UP TO EDITORIAL ILLUSTRATION}

\begin{abstract}
The vast universe of illustration and its manifestations in diverse media — such as publicity, commercial and cultural products design, internet and its derivatives, textile and editorial industries, among othershave given place, in the past years, to a particular interest for its study and professionalization in Mexico. In order to contribute to that goal, from an editorial perspective arises this brief study, which offers the comprehension of illustration far beyond the role of a decorative element inside the book. In this article we approach illustration from its formal definition, its origins, its development in México - through a very brief historical review - and its communicative structures. Such reflections are rarely made and constitute the key point for illustration practice. To reinforce this viewpoint and to throw a wider vision of illustration as a discipline, the fields of design and communication will help building the theoretical bases for its formal study. In a similar fashion, an emphasis on the reader's figure results fundamental to comprehend the graphic and communicative circuit of illustration that makes it a formal visual language that overtakes its container, the book, bringing it closer to subjectivity.
\end{abstract}

Keywords: editorial illustration, children books, design, communication.

Dol: http://doi.org/10.22201/codeic.16076079e.2019.v20n4.a1 


\section{Nayelli Herzel Arley Dávila}

Nació en la Ciudad de México el 6 de diciembre de 1982. Estudió la licenciatura en Diseño y Comunicación Visual en la Escuela Nacional de Artes Plásticas de la UNAM; obtuvo la especialidad en Diseño Editorial por la Escuela de Diseño del Instituto Nacional de Bellas Artes (INBA) y el diplomado en Ilustración por la Casa Universitaria del Libro, UNAM.

Ha colaborado en proyectos editoriales en Siglo XXı Editores, Gárgola Ediciones, Margen Rojo, entre otros independientes. Ha cursado varios cursos y talleres en tipografía, ilustración y diseño que han enriquecido su labor. En los últimos años se ha dedicado al collage como medio de expresión y experimentación técnica para proyectos independientes; asimismo, ha participado en exposiciones, talleres y eventos que promueven esta técnica.

Actualmente es ayudante de profesor en las asignaturas Diálogos transepistemológicos y Código abierto en la División de Posgrado de la Facultad de Artes y Diseño. Está en curso su obtención de grado de maestría por la misma Facultad con la investigación titulada "Contribuciones para un estudio formal de la ilustración en México: desarrollo y condición de la ilustración editorial infantil contemporánea y sus autores". 
En un país como México, inmerso en una herencia artística y en prácticas culturales que privilegian el quehacer del arte, ha sido fácil ingresar el diseño y la ilustración dentro de dichas prácticas sin reconocer su estructura y lenguaje propios. Esta postura conlleva a pormenorizar los conocimientos, los procesos y los alcances de sus contribuciones dentro de la cultura visual y para la formación de profesionales.

La importancia de la ilustración en el desarrollo de la visualidad y su influencia en nuestra época y país plantea la necesidad de establecer registros para su análisis y estudio formal a partir de sus componentes y su ejercicio como una manifestación cultural y como una disciplina cada vez más pujante en el ámbito del diseño y de la industria editorial.

Por medio de la ilustración editorial infantil exploraremos los diversos elementos que constituyen a la ilustración como un lenguaje particular con características y desarrollo propios, su relación con el diseño, su presencia en la industria editorial, y sus autores y lectores, con el objetivo de establecer fundamentos concretos para su estudio como una práctica formal en el ámbito profesional y fomentar su reconocimiento en la cultura visual de nuestro país.

\section{¿Qué es la ilustración editorial?}

Ilustración del latín illustrare significa sacar a la luz, iluminar, alumbrar, descubrir..., términos que aluden a una función de visibilidad. En ese sentido, podemos recurrir a la definición que plantea Nuria Obiols: un lenguaje artístico cuya razón de existir radica en su relación con el texto, compañero al que clarifica — saca a la luz-, explica — descubre - elabora y decora -ilumina- (Obiols, 2004). De acuerdo con estas definiciones y en aras de explicar a profundidad la ilustración editorial conviene resaltar las nociones de lenguaje y visibilidad, mismas que en su conjunción permiten la denominación del código que emplea la ilustración: el lenguaje visual. Por medio de este código la ilustración crea imágenes dentro de un contexto específico, en este caso el libro, que suma lo editorial al término. Por lo tanto, podemos decir que la ilustración editorial es un lenguaje visual que se emplea para la creación de imágenes dentro del libro. El carácter del libro puede ser diverso, sin embargo, el enfoque de este estudio está dirigido a los libros infantiles, particularmente los ilustrados.

La elección de este contexto deriva de la creciente presencia de la ilustración en los libros infantiles publicados en México en los últimos años y de la falta de estudio y registros sobre este tema desde el campo del diseño. Esta visión otorga una perspectiva distinta a la de la literatura, lo que permite trasladar la ilustración al mundo de las imágenes y de la comunicación visual, y da lugar a una comprensión más amplia de sus estructuras, lenguaje y alcances. 
Ilustración de Armando Fonseca del libro de poesía Un ajolote me dijo... ${ }^{1}$

${ }^{1}$ Baranda, María (2017). Un ajolote me dijo... (Armando Fonseca García, ilustrador). México: Castillo.

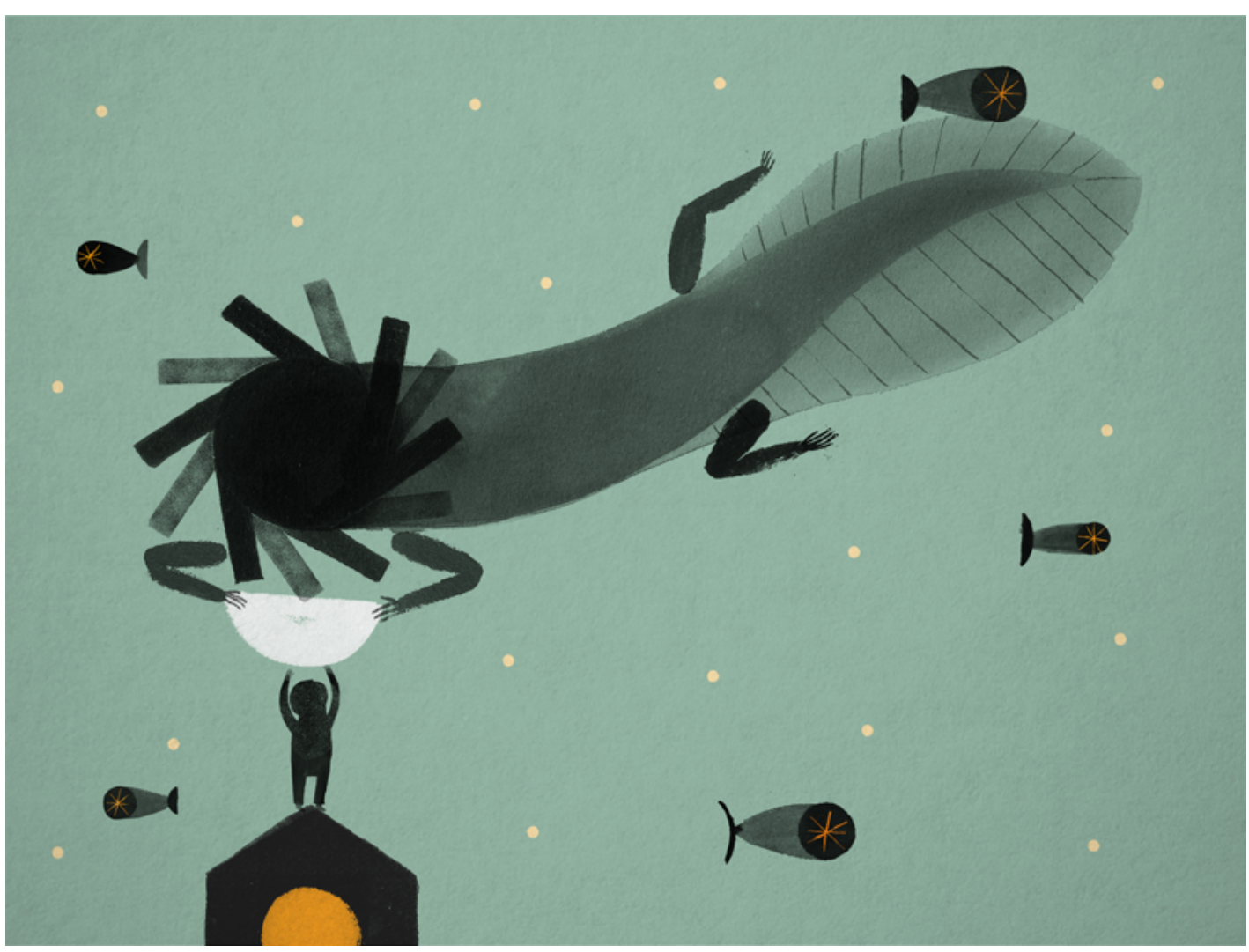

\section{Antecedentes de la ilustración editorial infantil en México}

Dos fenómenos importantes dan lugar a la ilustración editorial infantil:

1. El reconocimiento del niño como sujeto de derecho - a la educación y a una vida digna-.

2. El surgimiento de la literatura infantil y juvenil, a la que actualmente nos referimos como LIJ.

El primero dio acceso al niño a la esfera de lo político en donde es reconocido como sujeto con características y necesidades específicas, entre ellas la educación. Le abrió la posibilidad de ser considerado en los distintos programas educativos y culturales de los países adheridos a la Convención sobre los Derechos del Niño. En el caso de México, los niños comenzaron a ser considerados dentro de los programas educativos gracias a la visión —alfabetizadora primordialmentede la Secretaría de Educación Pública (SEP), creada al término de la Revolución Mexicana (1921) con la intención de combatir el rezago de la población en el ámbito educativo.

Los cambios en materia de educación y a favor de la población más joven se adoptaron desde la Constitución Política con la intención de llegar a toda la sociedad por igual, siendo fieles a los principios conquistados en 1917: educación libre, laica y gratuita. Sobre este fundamento diversas reformas al artículo $3^{\circ}$ 
1 "Artículo 3․ La educación que imparta el Estado será socialista, y además de excluir toda doctrina religiosa combatirá el fanatismo y los prejuicios, para lo cual la escuela organizará sus enseñanzas y actividades en forma que permita crear en la juventud un concepto racional y exacto del universo y de la vida social" (Secretaría de Gobernación)

2 "El gobierno de Lázaro Cárdenas acentuó el énfasis en la lectura popular. [...] mantuvo la lucha contra el analfabetismo que aún se registraba en 59 por ciento de la población mayor de diez años. Se editaron millones de textos de lectura [...]. Además el gobierno cardenista produjo dos series de libros que no tuvieron carácter de obligatorios: Simiente y la serie SEP" (GARMA, 2009: 33-35).

3 "Aquella que despierta y alimenta el gusto por la lectura; usualmente de carácter literario

[...] todos esos textos donde la experiencia humana es tema central" (Garrido, 2012).

${ }^{4}$ Especial mención en este ámbito merece Pascuala Corona quien en 1945 publicó

Cuentos mexicanos para niños; una edición independiente de historias adaptadas de la literatura tradicional "plagadas de elementos mexicanos y mestizos" (Dehesa, 2014: 21-23).

5 El Seminario Internacional de

Ilustración se ha llevado acabo cada dos años desde 2014 permitieron avances en el ámbito educativo y a favor de la cultura y la sociedad. Una de las primeras reformas ${ }^{1}$ realizadas sentó las bases para el surgimiento de distintos instrumentos que permitieran al Estado cumplir con los valores de libertad e igualdad en materia de educación, y combatir de manera frontal y acelerada el rezago en el que se había sumido la sociedad durante muchos años. El carácter socialista instaurado durante el período de Lázaro Cárdenas (1934-1940) otorgó una importancia fundamental al acceso a la cultura, por lo que además de la distribución de libros gratuitos en las escuelas se consideró la creación de libros dirigidos a la infancia, alejados de la función educativa que esencialmente presentaban los primeros materiales, y se dio prioridad a su distribución en zonas rurales.

Muestra de ello son las diversas colecciones no obligatorias que el gobierno impulsó a partir de este período presidencial para las escuelas, ${ }^{2}$ en donde los niños tuvieran acceso a libros que fomentaran la lectura recreativa. ${ }^{3}$ Este tipo de iniciativas y muchos otros esfuerzos de corte independiente ${ }^{4}$ que a lo largo del siglo se desarrollaron condujeron a la gestación de un nuevo nicho en la literatura: la Lı.

El reconocimiento de la infancia como público lector condujo a repensar la literatura. Para los escritores se abrió un nuevo sector y para los ilustradores un nuevo escenario sobre el cual brillar. De emplear un lenguaje moralizante y formativo, y estar restringida a temas "adecuados" para la infancia, la nueva literatura se permitió el abordar temas variados, de interés general, haciendo de lado las clasificaciones tradicionales de adultos y niños. De modo que hoy, la LI trata temas de toda índole: la vida, la muerte, las separaciones familiares, las emociones, la vida adulta, la existencia, etcétera. Esto supuso el comienzo de un cambio en la ilustración, que pasó de cumplir con un rol exclusivo de acompañamiento del texto y un lugar secundario en el ámbito editorial a un nuevo lenguaje en donde las imágenes comenzaron a ejercer un papel preponderante en la literatura.

Estos cambios en el panorama editorial y el nuevo entendimiento de la infancia y la juventud dieron a luz en 1981 a la Feria Internacional del Libro Infantil y Juvenil (FILIJ) que desde entonces ha promovido el surgimiento de autores - escritores e ilustradores - dedicados a la infancia, así como la creación de diversas editoriales que fomentan principalmente la lectura recreativa. En el mes de noviembre de 2018 se celebró la edición xxxvIII de la Feria en donde se llevó acabo, por tercera ocasión, el Seminario Internacional de llustración ${ }^{5}$ con sede en Ciudad de México y Oaxaca, evento en el que se imparten conferencias, talleres y clases magistrales de reconocidos ilustradores nacionales e internacionales. Este Seminario es fruto del esfuerzo realizado por editores, ilustradores, diseñadores y promotores de lectura, que en conjunto buscan otorgar a la ilustración un espacio de profesionalización y mayor reconocimiento dentro de la industria editorial. Entregada a esta labor, la Asociación Mexicana de llustradores (AMDI) funge un papel fundamental para el reconocimiento de los ilustradores dentro de 
\|lustración de Julio Torres para el libro Fiestas del Agua. Sones y leyendas de Tixtla.?

${ }^{6}$ En este año (1991) fue ratificada por México la Declaración sobre los Derechos de los Niños.

${ }^{7}$ Ejemplo de esto es el libro de Caterina Camastra y Héctor Vega (2012). Fiestas del Agua. Sones y leyendas de Tixtla (Julio Torres Lara, ilustrador). México: Ediciones El Naranjo.

8 "Un álbum ilustrado es texto, ilustraciones, diseño total. Es obra de manufactura y producto comercial; documento social, cultural, histórico y, antes que nada, es una experiencia para los niños. Como manifestación artística, se equilibra en el punto de interdependencia entre las imágenes y las palabras, en el despliegue simultáneo de dos páginas encontradas y en el drama de dar vuelta a la página" (Arizpe y Styles, 2013: 43). la industria al exponer de manera constante su trabajo —entre otras actividades que han favorecido al gremio_, con lo cual han logrado una mayor presencia en el panorama nacional.

Así como el siglo xx fue el precursor de la LIJ, el siglo xxl es el precursor de un lenguaje renovado: la ilustración editorial infantil. En México, puede apreciarse concretamente colecciones como A la Orilla del Viento del Fondo de Cultura Económica (FCE) que desde $1991^{6}$ promueve la literatura y la ilustración infantiles, apostando en gran medida por esta última con la creación de la colección Los Especiales de A la Orilla del Viento, constituida principalmente por álbumes ilustrados. Asimismo, varias editoriales independientes se han entregado a la labor de producir libros de gran calidad visual y narrativa dentro del ámbito de la LIJ. Entre ellas destacan CIDCLI, El Naranjo, Nostra Ediciones, Editorial 3 Abejas y Ediciones Tecolote, las cuales han hecho una labor encomiable de reconocimiento al trabajo de los ilustradores mexicanos.

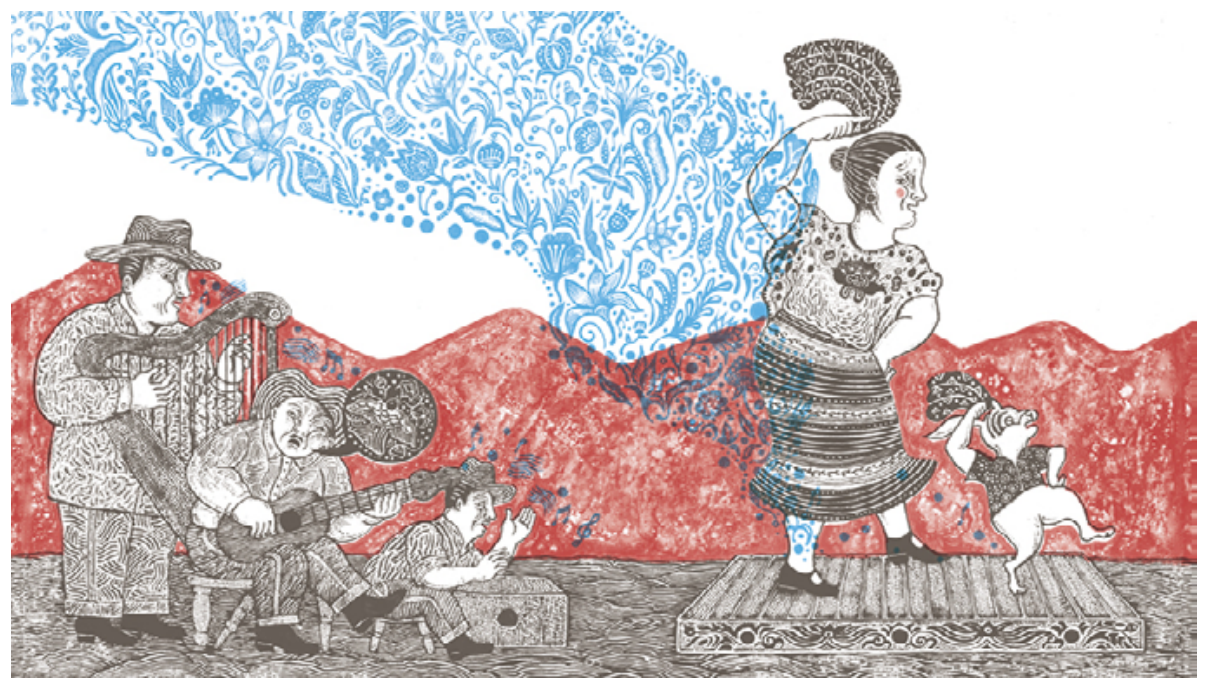

El (re)surgimiento de la ilustración como un lenguaje potenciado dentro de la LIJ abrió la posibilidad a nuevas exploraciones de la imagen y a una mayor relevancia de la misma dadas sus características narrativas y discursivas. Prueba de ello es el denominado libro-álbum o álbum ilustrado ${ }^{8}$ en el cual se narran historias a través de imágenes exclusivamente o donde la presencia del texto es mínima por lo que la ilustración dicta el camino de la narración. Este carácter protagónico de la imagen puso al descubierto a un nuevo lector con la capacidad de descifrar y conectarse a las historias por medio de la lectura de imágenes. Estos acontecimientos entorno a la ilustración suscitan el interés por explorar más a fondo su naturaleza comunicativa a través de campos como el de la imagen, la comunicación y el diseño, con el fin de conocer los elementos que intervienen en ella y sus alcances, como el lenguaje enriquecido y renovado que presenta en esta época. 
Figura 1. Esquema básico de la comunicación. Adaptación del esquema básico de la información de Claude

Shannon (1948), que muestra los elementos básicos que intervienen en la comunicación.

\footnotetext{
Figura 2. Esquema enriquecido de la comunicación I. Una adaptación del modelo de comunicación verbal de R. Jakobson (1958), que introduce las nociones de código y contexto, en el marco de la ilustración.
}

\section{Aproximaciones a un modelo comunicativo de la ilustración editorial}

La ilustración como lenguaje visual es una fuente de comunicación, la cual implica una práctica compleja que involucra procesos y elementos específicos que delimitan y definen su ejercicio dentro de un contexto, en este caso en el ámbito editorial. A partir de un modelo básico de comunicación se establecen los elementos que intervienen en su proceso comunicativo en donde el ilustrador es el emisor, la ilustración el mensaje y el lector es el receptor (ver figura 1).

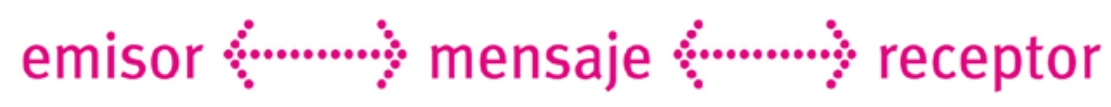

Sin embargo, es importante destacar que en el caso de la ilustración los agentes enunciados (emisor, mensaje y receptor) se encuentran inmersos en un contexto específico donde emisor y receptor se comunican a través de un código denominado lenguaje visual. A partir de esto se plantea un modelo comunicativo para la ilustración editorial, en donde se especifica el lugar de los actores, el contexto en el que se desarrolla y los elementos que intervienen en él (ver figura 2).

\section{LITERATURA INFANTIL}

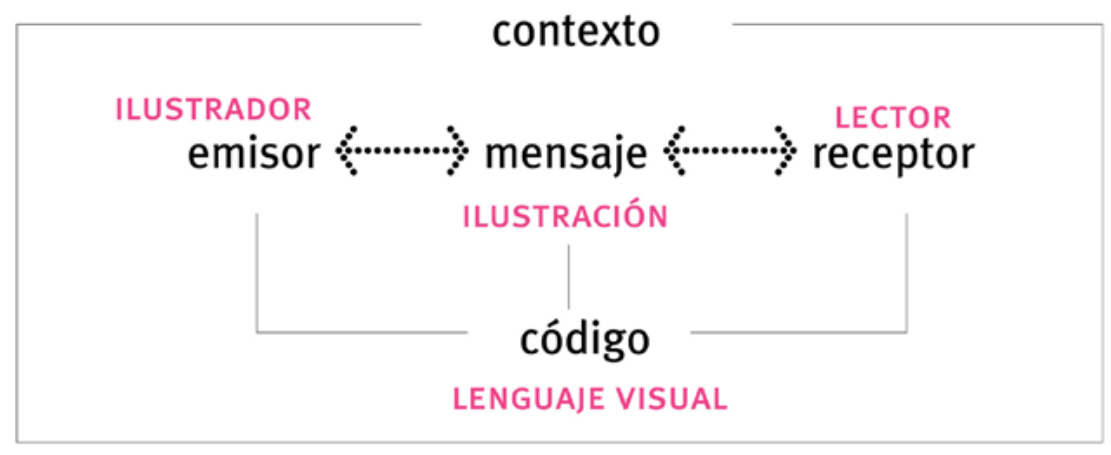

La noción de contexto sitúa al mensaje en un campo específico que conduce al estudio profundo de su articulación, dotándolo de características particulares como la definición específica del medio y el público al que va dirigido, en este caso el medio editorial y el público infantil.

La comunicación entre emisor y receptor a partir de un mensaje articulado en un código y contexto específicos da lugar a un intercambio, noción que conduce a una mayor subjetivación del esquema comunicativo: "Leer... es el arte de dar vida a la página, de establecer con un texto [mensaje] una relación amorosa en la cual experiencia íntima [receptor] y palabra ajena [emisor], el vocabulario propio [receptor] y la experiencia de otro [emisor], convergen y se entremezclan [intercambio] como las aguas de dos ríos y se funden en un solo caudal" (Manguel, 2007 cit. en Cerrillo, 2016).

El intercambio conduce al reconocimiento del receptor como un sujeto más completo que piensa y resignifica a partir del mensaje visual —la ilustración 
Figura 3. Esquema enriquecido de la comunicación II. Se introducen los conceptos de diálogo e intercambio propuestos por A. J. Greimas, elementos que de acuerdo con diversos autores "humanizan" la comunicación. De acuerdo con el modelo comunicativo para la ilustración editorial este diálogo/intercambio se establece entre lector e ilustrador a partir de la ilustración como mensaje. editorial infantil-y de su propia experiencia, y que da lugar a un esquema enriquecido de la comunicación como se presenta en la figura 3.

LITERATURA INFANTIL

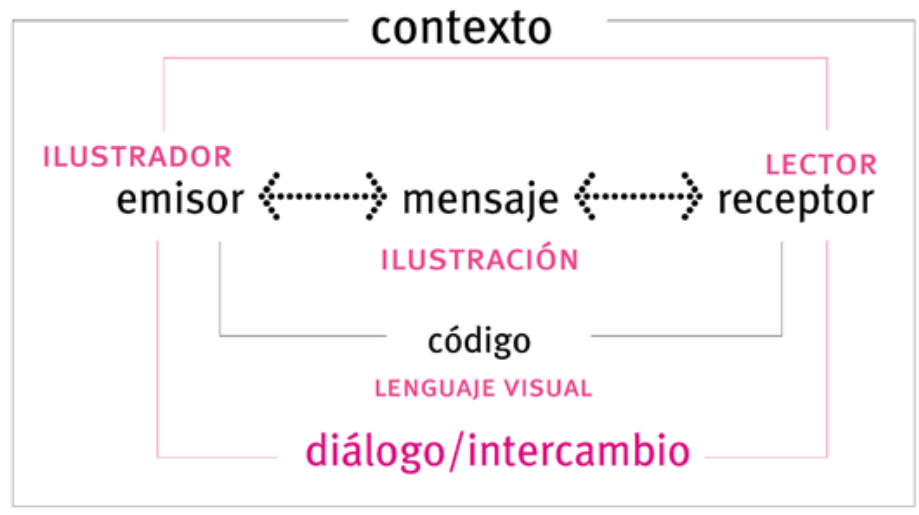

El diálogo que se establece entre emisor y receptor a través del mensaje da lugar a un intercambio subjetivo entre lo que expresa el primero y lo que el segundo comprende a partir de la información visual que se le ofrece, y aunado a sus propios conocimientos y experiencias encuentra "sentido" a lo que observa, generando así un conocimiento más significativo.

Varios autores afirman que la ilustración de calidad posee cualidades subjetivas que hablan a la emotividad y a la afectividad, que la ilustración:

[...] evoca sentimientos, estimula la inteligencia y la fantasía, incentiva la creatividad y el espíritu de observación y favorece la comparación, en una prueba visual, entre la imagen elaborada por el receptor en su interior y el dibujo reproducido en la página surgido de la invención creadora del artista; [...] es fuente de alegría, de gratificación interior (Nobile cit. en Obiols: 41).

En este proceso de significación resulta esencial el lector de la imagen, quien completa y enriquece el circuito de la comunicación. De esta manera, el modelo comunicativo de la ilustración se concreta, pues es quien le da sentido a las imágenes y afirma a la ilustración como un lenguaje que habla a lo íntimo, que transforma, que construye mundos visibles. ${ }^{9}$

Este último planteamiento desde el campo de la comunicación favorece a la ilustración, dotándola de un sujeto lector competente que la eleva junto con el diseño a un estatus de lenguaje visual formal con estructuras definidas, modeladas por entornos sociales y culturales específicos, que le conceden una mayor significación en el campo de la visualidad actual.

La importancia de la ilustración editorial infantil radica precisamente en el desarrollo de un nuevo lenguaje para la visualidad dentro del libro que evolucionó a partir de la Lı y que fomentó el surgimiento de más lectores y de la pericia de sus seguidores, hasta adquirir un papel esencial y protagónico dentro de la literatura en los últimos años. La evolución y trabajo constantes 
de esta disciplina en manos de profesionales permiten perfilarla hoy como un discurso visual que narra a través de imágenes. Es decir, como una práctica compleja con estructuras, herramientas y procesos específicos que habla desde y hacia la subjetividad, tendiendo puentes entre autores, ilustradores y lectores, y enriqueciendo el mundo editorial.

\section{Referencias}

- Arizpe, Evelyn y Styles, Morag (2013). Lectura de imágenes. Los niños interpretan textos visuales. Espacios para la lectura. México: FCE.

* Dehesa, Juana Inés (2014). Panorama de la literatura infantil y juvenil mexicana. México: CONACULTA.

* Garrido, Felipe (2012). Manual del buen promotor. Una guía para promover la lectura y la escritura. México: CONACULTA.

Greimas, A. J. (1987). Semiótica estructural. Madrid: Gredos.

* Garma, lleana (mayo, 2009). Historia de la literatura infantil. Alas para la equidad. Órgano informativo del Consejo Nacional de Fomento Educativo, 1(11), 33-35.

* Petit, Michèle (2014). Pero, ¿y qué buscan nuestros niños en los libros? México: CONACULTA.

* Secretaría de Gobernación (13 de diciembre de 1934). Diario Oficial. Órgano del Gobierno Constitucional de los Estados Unidos Mexicanos, tomo LXXXVII, núm. 35.

\section{Cómo citar este artículo}

* Arley Dávila, Nayelli Herzel (2019). Más allá de la imagen: una mirada cercana a la ilustración editorial. Revista Digital Universitaria (RDU). Vol. 20, núm. 4 julio-agosto. DOI: http://doi.org/10.22201/codeic.16076079e.2019.v20n4.a1. 